\title{
MEASUREMENT OF SAMPLE TEMPERATURES AND TEMPERATURE GRADIENTS IN MAGIC-ANGLE SPINNING NMR
}

\author{
Viktor HRONSKÝ \\ Department of Physics, Faculty of Electrical Engineering and Informatics, Technical University of Košice, \\ Park Komenského 2, 04200 Košice, Slovak Republic, \\ tel. +421 55602 2835, e-mail: viktor.hronsky@tuke.sk
}

\begin{abstract}
Determination of a true temperature and temperature gradient in the solid-state NMR sample is a serious problem in MAS and MAS NMR measurements which use a variable-temperature control unit (VT MAS NMR). In the presented article the method which takes advantage of a temperature dependence of ${ }^{207} \mathrm{~Pb} \mathrm{NMR}$ chemical shift of $\mathrm{Pb}\left(\mathrm{NO}_{3}\right)_{2}$ is proposed for the solution of this problem. Dependences of the sample temperature on the MAS rate at room temperature are reported as well as the measured and processed dependences of the sample temperature in the centre and edges of the rotor on the temperature set in the variable-temperature control unit (VT) measured at characteristic (frequently used) MAS rates of $10 \mathrm{kHz}$ and $6 \mathrm{kHz}$, respectively. Analysis of the $\mathrm{Pb}\left(\mathrm{NO}_{3}\right)_{2}$ spectra provided a maximal temperature gradient in a cylindrical sample as well as the temperature gradient in a narrow region (3 $\mathrm{mm}$ ) in the centre of the rotor. The results obtained can be used for calculation of the true sample temperature in specific VT MAS NMR experiments and contribute to understanding of principles of frictional heating at axial rotational motion of cylindrical objects in the gas atmosphere.
\end{abstract}

Keywords: solid-state NMR, magic-angle spinning, heating of samples, sample temperature, temperature gradients, Varian T3 MAS HXY probes

\section{INTRODUCTION}

The temperature of the sample placed in a rotor of the MAS probehead of a solid-state NMR spectrometer is an important parameter of NMR measurement. There are indications that the temperature inside the rotor can differ from temperature set in the variable-temperature control unit (VT) which is, due to the construction reasons, controlled by a thermocouple located outside of the rotor. During a real NMR measurement, temperature of the sample is modified due to frictional heating caused by rotation of the sample as well as by other factors, e.g., construction of the stator, bearing and drive system, and separation of the flow of heating medium. The sample can be also heated by radiofrequency irradiation and heteronuclear decoupling [1].

The temperature of the sample placed in a rotor is usually determined using a temperature dependence of the isotropic chemical shift, the width of resonance lines as well as the changes of chemical shift anisotropy parameters (at low MAS rates) of various calibration materials [1-12]. These procedures have been applied for Bruker, Jeol, and General Electric spectrometers. Sample heating in these spectrometers is carried out using bearing or/and drive gases.

The aim of this study was to propose a method which can be used for determination of the temperature and temperature gradients in samples placed in rotors of Varian T3 MAS HXY probeheads which have a different system for heating and cooling the samples. In this case, the flow of heating (cooling) medium is separated and directed to the centre of spinning rotor. Based on the results reported in this article, this system of heating (cooling) gives different results in comparison with those used in the above mentioned spectrometers as far as temperature characteristics and temperature gradients are concerned.
$\mathrm{Pb}\left(\mathrm{NO}_{3}\right)_{2}$ was chosen as a calibration material due to the fact that it has a strong temperature dependence of the isotropic chemical shift [6].

\section{EXPERIMENTAL}

A standard $4 \mathrm{~mm}$ zirconium dioxide rotor with vespel drive cap and teflon spacers were used for Varian T3 MAS HXY probehead.

The calibration material, $\mathrm{Pb}\left(\mathrm{NO}_{3}\right)_{2}$, with purity of 99.999\%, was purchased from Aldrich. To determine the temperature and temperature gradients more exactly and prevent expected line broadening, the volume of the rotor was filled with $\mathrm{Pb}\left(\mathrm{NO}_{3}\right)_{2}$ only to approximately 20 percent. Additional teflon cylinders inserted into the rotor created a $3 \mathrm{~mm}$ wide empty gap in the middle of rotor and $1 \mathrm{~mm}$ wide empty gap at one edge of the rotor. These gaps were filled with $\mathrm{Pb}\left(\mathrm{NO}_{3}\right)_{2}$ (Fig. 4). This spacing of calibration material made it possible to determine exactly the temperatures in the centre and edge of the rotor and simultaneously also the temperature gradient in $3 \mathrm{~mm}$ space in the middle of rotor.

${ }^{207} \mathrm{~Pb}$ MAS NMR spectra were measured on a 400 $\mathrm{MHz}$ Varian Solid State NMR spectrometer (magnetic field of $9.4 \mathrm{~T}$ ). Measurements were performed at resonance frequency of $83.35 \mathrm{MHz}$ with a $\pi / 2$ pulse duration $3.5 \mu \mathrm{s}$, recycle delay $40 \mathrm{~s}$, and acquisition time 82 ms. The number of accumulation was always 128 . Varian Vnmrj 3.2 and MestReNova 8 software were used for NMR measurement control and processing of obtained spectra, respectively.

The spectra were measured at different temperatures and different MAS rates; waiting time for temperature stabilization was $30 \mathrm{~min}$. To obtain information on the type of chemical shift anisotropy, a static NMR spectrum of $\mathrm{Pb}\left(\mathrm{NO}_{3}\right)_{2}$ was also measured. At each MAS measurement, the bearing and drive gas flow rates were 
set manually to values according to a Varian calibration graph, and VT flow was kept constant at $20 \mathrm{~L} / \mathrm{min}$.

\section{RESULTS AND DISCUSSION}

The static NMR spectrum of the calibration sample measured at room temperature is shown in Fig. 1. The spectrum displays a broad NMR signal with a distinct axial anisotropy of the chemical shift tensor. In spite of the fact that principal values of the chemical shift tensor and anisotropy parameter $\delta$ change considerably with the temperature, these parameters can be used for the calibration of temperature only in VT experiments with non-spinning sample $[6,7,11]$.

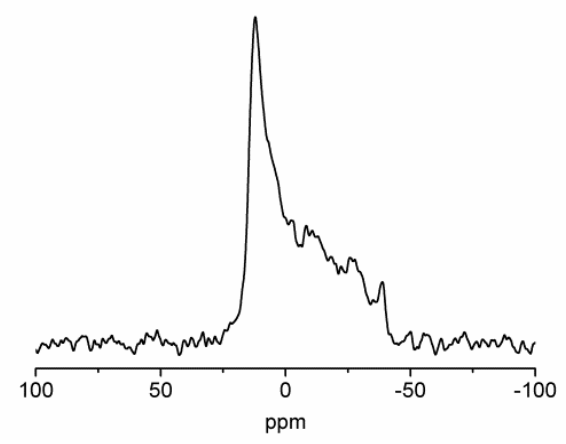

Fig. 1 Experimental ${ }^{207} \mathrm{~Pb}$ NMR spectrum of non-spinning $\mathrm{Pb}\left(\mathrm{NO}_{3}\right)_{2}$ sample measured at $25^{\circ} \mathrm{C}$

Fig. 2 shows selected ${ }^{207} \mathrm{~Pb}$ MAS NMR spectra, whose processed parameters are depicted in Fig. 3. When temperature was constant in the whole volume of the sample, $\mathrm{Pb}\left(\mathrm{NO}_{3}\right)_{2}$ produced a very narrow symmetrical signal with the half-width of $30 \mathrm{~Hz}(0.36 \mathrm{ppm})$ at the MAS rate of $1220 \mathrm{~Hz}$. Spectra measured at lower MAS rates displayed broader lines due to not sufficiently suppressed chemical shift anisotropy.

With increasing the MAS rate, the viscous drag of the rotor comes into effect which results in the heating of the rotor and subsequently also the sample. Due to the presence of several gas flows (heating, bearing, and driving flows), the temperature increase in different parts of the sample at specific MAS rate (when VT is adjusted to $25^{\circ} \mathrm{C}$ ) is not uniform. The temperature increase in the centre of the rotor differs from that at its edge. The spectra shown in Figs. 2 b), c), and d) display an additional peak corresponding to the signal of the sample from the edge of the rotor. When information on the temperature change of ${ }^{207} \mathrm{~Pb}$ chemical shift in lead nitrate $(0.753 \mathrm{ppm} / \mathrm{K})$ [6] is taken into account, it is possible to conclude that temperature of the sample in the whole volume of the rotor is constant up to the MAS rate of $2 \mathrm{kHz}$ and equal to the temperature set in the VT control unit. Temperature of bearing and drive gases was set to $24{ }^{\circ} \mathrm{C}$ in these measurements. With increasing the MAS rate (Fig. 3), the temperature of the sample increased strongly $-+7.6{ }^{\circ} \mathrm{C}$ in the centre of the rotor and $+5.9{ }^{\circ} \mathrm{C}$ at the edge of this, at $10 \mathrm{kHz}$. The temperature gradient in the $3 \mathrm{~mm}$ central region of the rotor was approximately $1^{\circ} \mathrm{C}$.

The signal reference of ${ }^{207} \mathrm{~Pb}$ in lead nitrate at $25^{\circ} \mathrm{C}$ was determined from the fitting curve in Fig. 3 as the value corresponding to the MAS rate of $0 \mathrm{~Hz}$. An excellent fitting by second-order polynomial points to the fact that the main factor influencing temperature within the sample is a kinetic energy of the rotor surface. The extrapolated value of $-4.205 \mathrm{ppm}$ at $25{ }^{\circ} \mathrm{C}$, together with above mentioned value of $0.753 \mathrm{ppm} / \mathrm{K}$, were used to calculate a theoretical function depicted in Fig. 5.

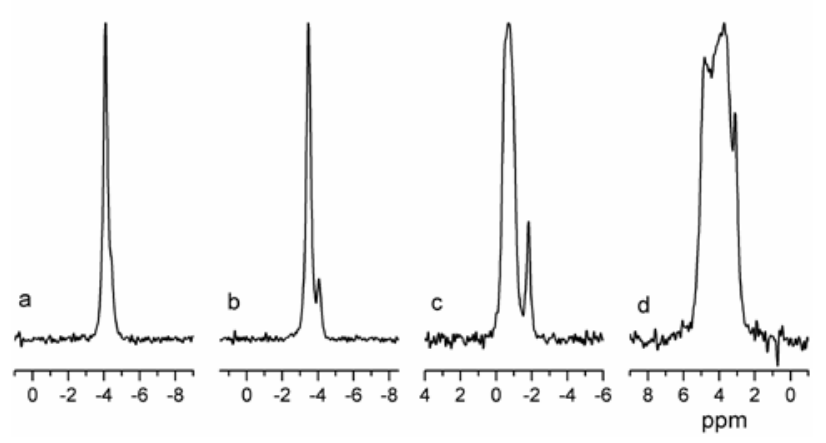

Fig. $2{ }^{207} \mathrm{~Pb}$ NMR spectra of $\mathrm{Pb}\left(\mathrm{NO}_{3}\right)_{2}$ measured at $25^{\circ} \mathrm{C}$ set in the VT control unit and MAS rates of a) $2 \mathrm{kHz}, \mathrm{b}) 4 \mathrm{kHz}$, c) 8 $\mathrm{kHz}$, and d) $12 \mathrm{kHz}$

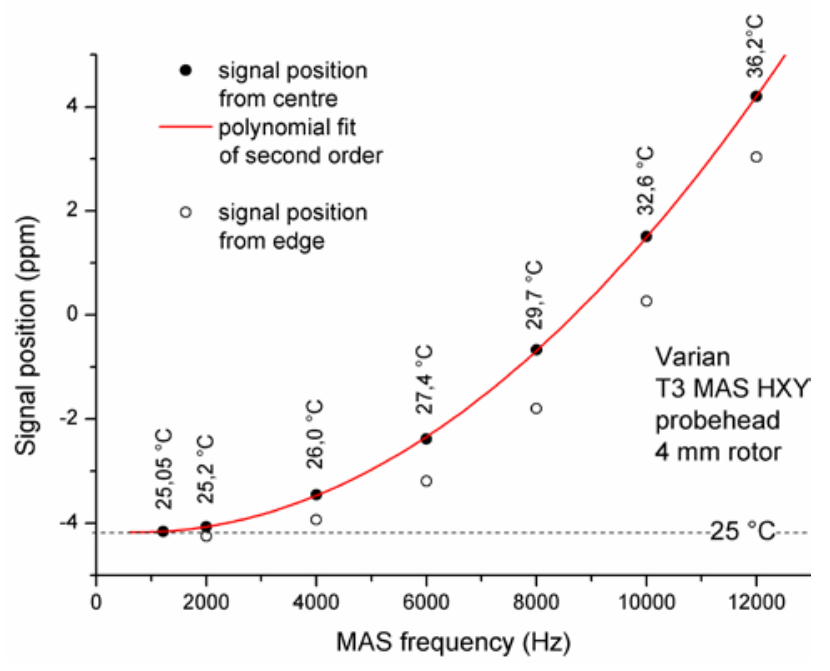

Fig. $3{ }^{207} \mathrm{~Pb}$ NMR chemical shifts of $\mathrm{Pb}\left(\mathrm{NO}_{3}\right)_{2}$ and the sample temperature in the centre (solid circles) and edge (open circles) of the rotor as a function of the MAS rate. The measurements were carried out at VT temperature set to $25^{\circ} \mathrm{C}$

The aim of following experiments was to determine a true temperature of the sample in the centre and edge of the rotor as well as temperature gradients at different VT temperatures. The probe arrangement provides that bearing and drive gas temperatures are approximately the same. In our measurements, they always were about $24{ }^{\circ} \mathrm{C}$ (as RT).

The NMR measurements were carried out at VT temperatures from 25 to $175^{\circ} \mathrm{C}$ at two MAS rates $-6 \mathrm{kHz}$ and $10 \mathrm{kHz}$. The following section deals in detail with the measurements performed at MAS rate of $10 \mathrm{kHz}$.

A stabilization of the temperature at higher MAS rates is influenced substantially by a cooling effect of the bearing and drive gas flows. The ${ }^{207} \mathrm{~Pb}$ MAS NMR spectra of lead nitrate measured at different temperatures are depicted in Fig. 4, and their processing is shown in Fig. 5. An interesting line narrowing observed in spectra at certain temperatures indikates that temperature gradient in 
the central part of the rotor $(3 \mathrm{~mm}$ ) is minimal at these temperatures. From Fig. 5 can be inferred that it is observed in a temperature range in which temperature of the sample in the centre of rotor is approximately the same as temperature of the heating gas in the VT control unit.

Fig. 5 displays ${ }^{207} \mathrm{~Pb}$ chemical shifts of $\mathrm{Pb}\left(\mathrm{NO}_{3}\right)_{2}$ sample placed in the centre and at the edge of the rotor versus VT temperature and derived straight lines fitting this dependences. These straight line equations shown in Fig. 5 allow to calculate a true temperature of the sample if VT temperature is known.

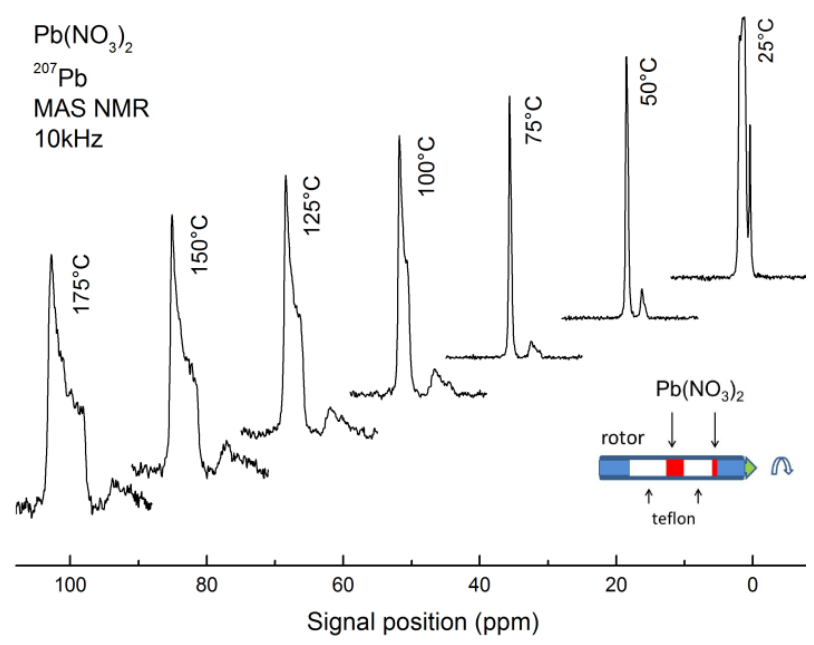

Fig. $4{ }^{207} \mathrm{~Pb}$ NMR spectra of $\mathrm{Pb}\left(\mathrm{NO}_{3}\right)_{2}$ sample measured at different VT temperatures at constant MAS rate of $10 \mathrm{kHz}$

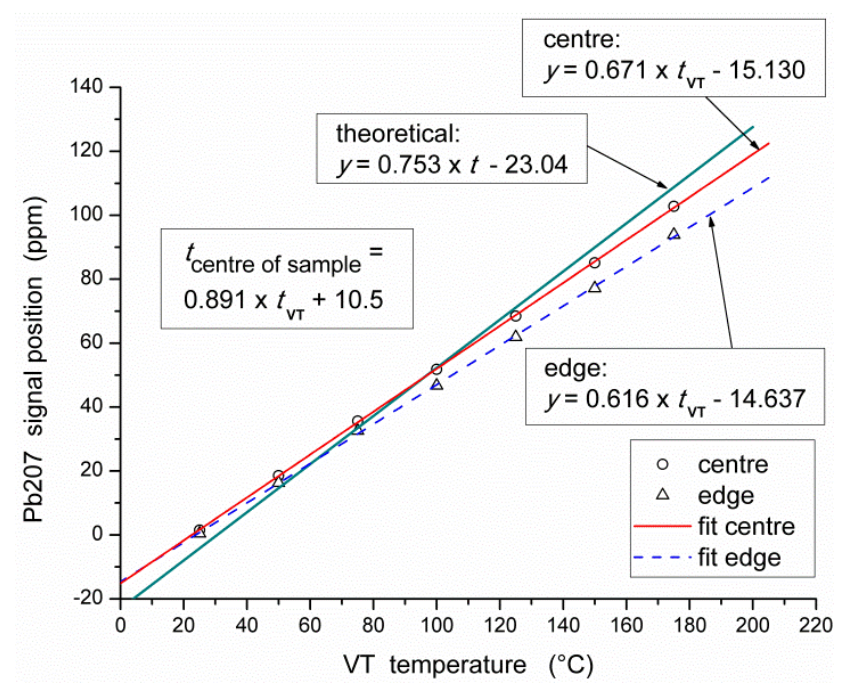

Fig. $5{ }^{207} \mathrm{~Pb}$ chemical shift of $\mathrm{Pb}\left(\mathrm{NO}_{3}\right)_{2}$ sample placed in the centre and at the edge of the rotor versus VT temperature. Fitting straight lines and corresponding straight line equations for MAS rate of $10 \mathrm{kHz}$

When a certain value of VT temperature is set then a true temperature of the sample in the centre and at the edge of the rotor can be calculated using the following formulae:

$$
t_{\text {centre of sample }}=0.891 \times t_{\mathrm{VT}}+10.5
$$

$$
t_{\text {edge of sample }}=0.818 \times t_{\mathrm{VT}}+11.2
$$

Maximal temperature gradient of the sample in a fully filled rotor is given by the following formula:

$$
\Delta t_{\text {max }}=t_{\text {centre }}-t_{\text {edge }}=0.073 \times t_{\mathrm{VT}}-0.7
$$

If, for example, VT temperature is set to $50{ }^{\circ} \mathrm{C}$ then the maximal temperature gradient in the sample is only $3{ }^{\circ} \mathrm{C}$, but if VT temperature is set to $150{ }^{\circ} \mathrm{C}$ then the temperature gradient in the sample reaches $10.2{ }^{\circ} \mathrm{C}$. Temperature gradients in the central part of the rotor (3 $\mathrm{mm}$ ) can be calculated from the line widths of the signals in the left part of the spectra in Fig. 4.

If a certain temperature is required in the sample (in the centre of the rotor) then the corresponding VT temperature can be calculated by an equation:

$$
t_{\mathrm{VT}}=1.122 \times t_{\text {centre of sample }}-11.8
$$

The results of analogous measurements performed at the MAS rate of $6 \mathrm{kHz}$ (often used at cross-polarisation experiments) processed as mentioned above, and fitting straight lines with calculated parameters are shown in Fig. 6.

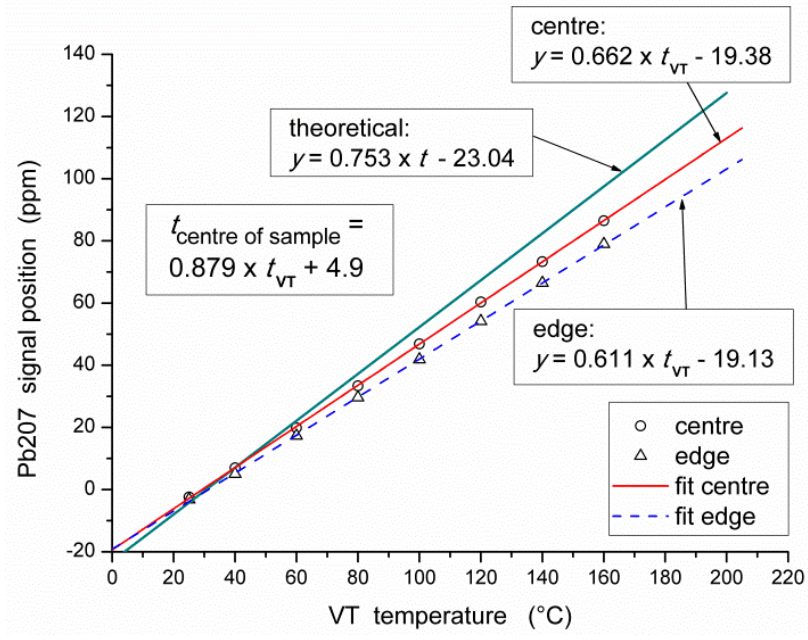

Fig. $6{ }^{207} \mathrm{~Pb}$ chemical shift of $\mathrm{Pb}\left(\mathrm{NO}_{3}\right)_{2}$ sample placed in the centre and at the edge of the rotor versus VT temperature. Fitting straight lines and corresponding straight line equations for MAS rate of $6 \mathrm{kHz}$

$$
\begin{gathered}
t_{\text {centre of sample }}=0.879 \times t_{\mathrm{VT}}+4.9 \\
t_{\text {edge of sample }}=0.811 \times t_{\mathrm{VT}}+5.2 \\
\Delta t_{\text {max }}=t_{\text {centre }}-t_{\text {edge }}=0.068 \times t_{V T}-0.3 \\
t_{\mathrm{VT}}=1.138 \times t_{\text {centre of sample }}-5.5
\end{gathered}
$$

The results summarized in Fig. 5 and Fig. 6 show that at lower temperatures, the temperature of the sample is higher than VT temperature, and at higher temperatures, the situation is opposite. This is a substantial difference with respect to the probeheads of Bruker, Jeol, and General Electric spectrometers in which the temperature 
of the sample is always higher than the VT temperature (when set above RT).

\section{CONCLUSIONS}

In the article, the method which takes advantage of the temperature dependence of ${ }^{207} \mathrm{~Pb}$ NMR chemical shift of $\mathrm{Pb}\left(\mathrm{NO}_{3}\right)_{2}$ is proposed for the calculation of a true temperature and temperature gradient in the sample at VT MAS NMR measurements. The dependence of the temperature increase of the sample on MAS rate obeys second-order polynomial due to the effect of frictional heating. Behaviour of temperature of the sample heated by VT gas in a Varian probehead differs from those published for probeheads of spectrometers of other types. The most important outcomes of this study are fitting functions which allow to estimate the true temperature in the profile of the sample and also to calculate VT temperature when a specific temperature in the sample is required in VT MAS NMR measurements.

\section{ACKNOWLEDGMENT}

The "We support research activities in Slovakia" project is co-financed from EU funds. This paper was developed as part of the project named "Centre of Excellence for Integrated Research \& Exploitation of Advanced Materials and Technologies in Automotive Electronics”, ITMS 26220120055.

\section{REFERENCES}

[1] DVINSKIKH, S. V. - CASTRO, V. SANDSTRÖM, D.: Heating caused by radiofrequency irradiation and sample rotation in ${ }^{13} \mathrm{C}$ magic angle spinning NMR studies of lipid membranes, Magn. Res. Chem., no. 42, pp. 875-881, 2004.

[2] HAW, J. F. - CROOK, R. A. - CROSBY, R. C.: Solid-solid phase transitions for temperature calibration in magic-angle spinning, J. Magn. Res., no. 66, pp. 551-554, 1986.

[3] AGUILAR-PARRILLA, F. - WEHRLE, B. BRAUNLING, H. - LIMBACH, H. H.: Temperature gradients and sample heating in variable temperaturehigh speed MAS NMR spectroscopy, $J$. Magn. Res., no. 87, pp. 592-597, 1990.

[4] PAN, H. - GERSTEIN, B. C.: NMR of ${ }^{31} \mathrm{P}$ in (VO) ${ }_{2} \mathrm{P}_{2} \mathrm{O}_{7}$ as an internal temperature standard in high-temperature NMR, J. Magn. Res., no. 92, pp. 618-619, 1991.

[5] GREY, C. P. - CHEETHAM, A. K. - DOBSON, C. M.: Temperature-dependent solid-state ${ }^{119} \mathrm{Sn}$ MAS NMR of $\mathrm{Nd}_{2} \mathrm{Sn}_{2} \mathrm{O}_{7}, \mathrm{Sm}_{2} \mathrm{Sn}_{2} \mathrm{O}_{7}$, and $\mathrm{Y}_{1.8} \mathrm{Sm}_{0.2} \mathrm{Sn}_{2} \mathrm{O}_{7}$. Three sensitive chemical-shift thermometers, $J$. Magn. Res., no. A101, pp. 299-306, 1993.
[6] BIELECKI, A. - BURUM, D. P.: Temperature dependence of ${ }^{207} \mathrm{~Pb}$ MAS spectra of solid lead nitrate. An accurate, sensitive thermometer for variable-temperature MAS, J. Magn. Res., no. A116, pp. 215-220, 1995.

[7] NEUE, G. - DYBOWSKI, C. - SMITH, M. L. HEPP, M. A. - PERRY, D. L.: Determination of ${ }^{207} \mathrm{~Pb}^{2+}$ chemical shift tensors from precise powder lineshape analysis, Solid State Nucl. Magn. Reson., no. 6, pp. 241-250, 1996.

[8] ZUO, C. S. - METZ, K. R. - SUN, Y. - SHERRY, A. D.: NMR temperature measurements using a paramagnetic lanthanide complex, J. Magn. Res., no. 133, pp. 53-60, 1998.

[9] LANGER, B. - SCHNELL, I. - SPIESS, H. W. GRIMMER, A. R.: Temperature calibration under ultrafast MAS conditions, J. Magn. Res., no. 138, pp. 53-60, 1998.

[10] TAKAHASHI, T. - KAWASHIMA, H. SUGISAWA, H. - BABA, T.: ${ }^{207} \mathrm{~Pb}$ chemical shift thermometer at high temperature for magic angle spinning experiments, Solid State Nucl. Magn. Reson. no. 15, pp. 119-123, 1999.

[11] BRUS, J.: Heating of samples induced by fast magicangle spinning, Solid State Nucl. Magn. Reson., no. 16, pp. 151-160, 2000.

[12] CONCISTRÈ, M. - GANSMÜLLER, A. MCLEAN, N. - JOHANNESSEN, O. G. MONTESINOS, I. M. - BOVEE-GEURTS, P. H. M. - VERDEGEM, P. - JOHAN LUGTENBURG, J. BROWN, R. C. D. - DEGRIP, W. J. - LEVITT, M. H.: Double-quantum ${ }^{13} \mathrm{C}$ nuclear magnetic resonance of bathorhodopsin, the first photointermediate in mammalian vision, J. Am. Chem. Soc., no. 130, pp. 10490-10491, 2008.

Received December 4, 2012, accepted January 15, 2013

\section{BIOGRAPHY}

Viktor Hronský was born on 6.2.1951. In 1975 he graduated (MSc) from the Faculty of Mathematics and Physics, Charles University, Praha. He defended his PhD in the field of physics in 1987, his thesis title was "Electron Paramagnetic Resonance Study of $\mathrm{Mn}^{2+}, \mathrm{Cu}^{2+}$ and $\mathrm{VO}^{2+}$ ions adsorption”. Since 1975 he has been working as an assistant professor at the Department of Physics, Faculty of Electrical Engineering and Informatics, Technical University of Košice. His scientific research is focused on NMR study of polymers, zeolites, aluminosilicates and related materials; in addition, he also works in the field of dielectric spectroscopy in solids. 